\title{
Fouling control in a gravity-driven membrane (GDM) bioreactor treating primary wastewater by using relaxation and/or air scouring
}

\author{
Luca Fortunato $^{\mathrm{a}, *}$, Luigi Ranieri ${ }^{\mathrm{a}}$, Vincenzo Naddeo ${ }^{\mathrm{b}}$, TorOve Leiknes ${ }^{\mathrm{a}}$ \\ ${ }^{a}$ Water Desalination and Reuse Center (WDRC), Division of Biological \& Environmental Science \& Engineering (BESE), 4700 King Abdullah University of Science and Technology (KAUST), \\ Thuwal, 23955-6900, Saudi Arabia \\ b SEED - Sanitary Environmental Engineering Division, Department of Civil Engineering, University of Salerno, via Giovanni Paolo II, Fisciano, SA, Italy
}

\section{A R T I C L E I N F O}

\section{Keywords}

Fouling mitigation

Cake layer

MBR

OCT

Biopolymers

\begin{abstract}
A B S T R A C T
Gravity-driven membrane bioreactors (GD-MBR) have been proposed as a sustainable water treatment due to the low energy requirements in terms of operation. The objective of this study is to investigate the effect of different physical cleaning strategies on the membrane performance in a gravity-driven membrane bioreactor treating primary wastewater. The Optical Coherence Tomography (OCT) allowed evaluating the impact of the physical cleaning on the biomass developed on the membrane surface. Applying relaxation did not enhance the membrane performance, however, it led to an increase in thickness and a decrease in the biomass specific hydraulic resistance. Using air scouring under continuous filtration increased the biomass specific hydraulic resistance by compressing the biomass ( $\sim 50 \%$ decrease in thickness). When air scouring was applied at the end of a relaxation cycle, a higher biomass removal and a significant increase in flux (250\%) were observed. Biopolymers were found to constitute $55 \%$ of the fouling layer. This study highlighted the suitability of an in-situ monitoring approach as a key tool to evaluate the impact of different physical cleaning strategies on the biomass removal in membrane filtration process.
\end{abstract}

\section{Introduction}

In the last century, the global demand for fresh water has steadily increased due to population growth and increase in economic activities. In the last 4-5 decades, the use of membrane processes has been considered a reliable solution to enhance the purification of water, particularly from non-conventional sources. Gravity-driven membrane (GDM) processes have recently been proposed as a sustainable alternative for water treatment due to the low energy requirements in terms of filtration operation [1]. Initially, the technology was proposed for household drinking water treatment [2]. Subsequently, GDM systems have been adapted and used for the treatment of different types of water such as rainwater [3], diluted wastewater [4,5], for greywater treatment [6] and as pretreatment for seawater RO desalination [7-9]. Regardless of the type of water treated, the GDM systems have been operated with different types of membranes and process configurations. Both external and submerged configurations have been investigated, using either hollow fiber membrane (HF) or flat sheet membrane (FS) modules, made with both microfiltration (MF) membranes (i.e. pore size in the range of $0.1-10 \mu \mathrm{m}$ ) and ultrafiltration (UF) membranes (i.e. pore size in the range of 5-100 nm) [1].

\footnotetext{
* Corresponding author.

E-mail address: luca.fortunato@kaust.edu.sa (L. Fortunato)
}

The performance of a GDM system is characterized by achieving a low and constant membrane flux which is maintained over a long-term filtration operation without the use of any membrane cleaning. A membrane flux in the range of 3-5 LMH was achieved by treating a feed water with $3-8 \mathrm{mg} / \mathrm{L}$ of DOC [10]. In spite of low membrane flux, the GDM systems present low operating energy and higher sustainability. The process is considered suitable for decentralized systems due to the easier operation compared to conventional MBR. Reports in the literature show that the permeate flux tends to stabilize over time, reaching a stable flux after 2 or 3 weeks of operation [7,11]. GD-MBRs combine membrane filtration with biological processes, where the flux stabilization is linked to the development of biomass on the membrane surface [12]. During the filtration process, microorganisms, inorganic, and organic material accumulate on the membrane surface, leading to an increase in hydraulic resistance [1].

The morphology of the cake layer deposited on the membrane is predominantly biomass and has been characterized by means of different techniques. Confocal laser scanning microscopy (CLSM) has been widely used to investigate the structure and biofilm composition by staining the samples with fluorescent dyes $[13,14]$. Recently, Optical Coherence Tomography (OCT), has been employed in GDM processes to in-situ and non-invasively monitor the biofilm structure during con- 
tinuous operation. Through the use of backscattering light, the OCT allows acquiring cross-sectional scans of the membrane. OCT enables studying the development of the fouling layer on the membrane surface non-invasively without the use of any contrast agents. Image analysis of the acquired OCT scans is then performed to assess the evolution of the fouling layer morphology over time [15].

The structure and amount of biomass deposited on the membrane surface in GDM systems are linked to different process parameters. In particular, the feed water quality (Table S1) has a direct impact on the biomass structure and therefore on the membrane performance [1]. An increase of organic content in the feed water results in a lower stable flux at steady state [4]. Peter-Varbanets et al. [16] studied the effect of dissolved oxygen (DO) in a GDM system, and observed that DO-limiting conditions led to a compact biomass morphology with high hydraulic resistance. Low DO conditions also influenced the biological activity and therefore the biofilm layer morphology. The biological activity in GDM systems can also be influenced by other parameters including feed water temperature [7]. Recently, the integration of GDM with other processes has been proposed as a method to enhance the membrane performance and permeate water quality. Ding et al., evaluated the use of granular activated carbon (GAC) or sand layer in a GD-MBR [3]. An increase in removal efficiency and decrease in flux observed were related to the formation of a denser bio-fouling layer.

In the case of submerged reactors (i.e. MBR), membrane performance is usually improved by using fouling mitigation strategies for fouling control. The physical cleaning consists of different strategies, such as relaxation, backwash, and air scouring. Relaxation improves the membrane productivity by inducing a detachment of the fouling layer formed on the membrane surface [17]. Backwashing consists of applying a backflow through the membrane, resulting in a temporarily and partially removal of the fouling layer deposited on the membrane $[18,19]$. Air scouring is used to remove a fouling layer formed on the membrane surface through generating local shear forces as the bubbles pass near the surface, and is applied both continuously and intermittently [20]. Recently, Lee et al. [21] evaluated the effect of intermittent aeration in a GD-MBR with biocarriers for wastewater reclamation.

The aim of this study is to investigate the effect of different physical cleaning strategies in a gravity-driven membrane bioreactor (GD-MBR) treating real wastewater. Relaxation and air scouring were introduced in the membrane reactor and operated for 23 days without any cleaning. Membrane performance (i.e. flux) and the permeate quality were measured at regular intervals to evaluate the impact of the fouling mitigation technique applied on the GDM process. OCT imaging was used to evaluate in-situ and in real-time the effect of each fouling mitiga- tion strategy on the evolution of the biomass morphology formed on the membrane surface during the period of operation.

\section{Materials and methods}

\subsection{Gravity-driven membrane bioreactor (GD-MBR) setup}

The submerged membrane reactors employed in this study consisted of a $70 \mathrm{~cm}$ high rectangular tank with a submerged FS ultrafiltration (UF) membrane module. The UF membrane (manufactured by MemSis Turkey) was made from polysulfone (PS), with $20 \mathrm{KDa}$ molecular weight cut-off (MWCO), having a membrane area of $0.0468 \mathrm{~m}^{2}(30 \mathrm{~cm}$ height and $15.6 \mathrm{~cm}$ width). The water head of $25 \mathrm{~cm}$ above the membrane was kept constant by using a level regulator. Considering the gradient along the length of the submerged module (30 cm height), the hydraulic pressure was calculated in the middle point of the membrane $(25 \mathrm{~cm}+15 \mathrm{~cm}=40 \mathrm{~cm})$. Hence the average hydraulic pressure was $40 \mathrm{mbar}$ (i.e. corresponding to water head of $40 \mathrm{~cm}$ above the center of the membrane module). The reactor was operated under ambient conditions at a room temperature of $22{ }^{\circ} \mathrm{C}$. The experimental configuration is shown in Fig. 1.

Primary effluent wastewater (WW) collected from the equalization tank of the wastewater treatment plant (WWTP) at KAUST - King Abdullah University of Science and Technology, Thuwal, Saudi Arabia, was used as feed (Table S1). The weight of the collected permeate was monitored every day to estimate the average daily volume collected and to calculate the average daily flux during filtration. Solenoid valves were employed to control the relaxation and the air scouring. The valves were connect to a National Instruments (NI) data acquisition system and controlled by using LabVIEW software.

The GD-MBR system was operated for 59 days, the different physical cleaning strategies applied are reported in Table 1 and Fig. 1 . In phase I (1-21 days) the GD-MBR was operated without applying any cleaning strategy. In phase II (21-35 days), a daily relaxation cycle of $6 \mathrm{~h}$ relaxation every $18 \mathrm{~h}$ was applied. In phase III (35-43 days), the relaxation frequency was increased with cycles of 15 min relaxation every $45 \mathrm{~min}$ filtration (maintaining the same daily overall filtration time). In phase IV (43-51 days), intermittent air scouring of 5 min every 25 min with an airflow intensity of $8 \mathrm{~L} / \mathrm{min}$ was introduced during continuous filtration [22]. In phase V (51-59 days), a combined physical cleaning strategy was introduced every $30 \mathrm{~min}$ of filtration, consisting of $25 \mathrm{~min}$ relaxation and the last $5 \mathrm{~min}$ of relaxation combined with air scouring.

Water samples were collected periodically from the feed tank and the permeate. The dissolved organic carbon (DOC) was measured af-

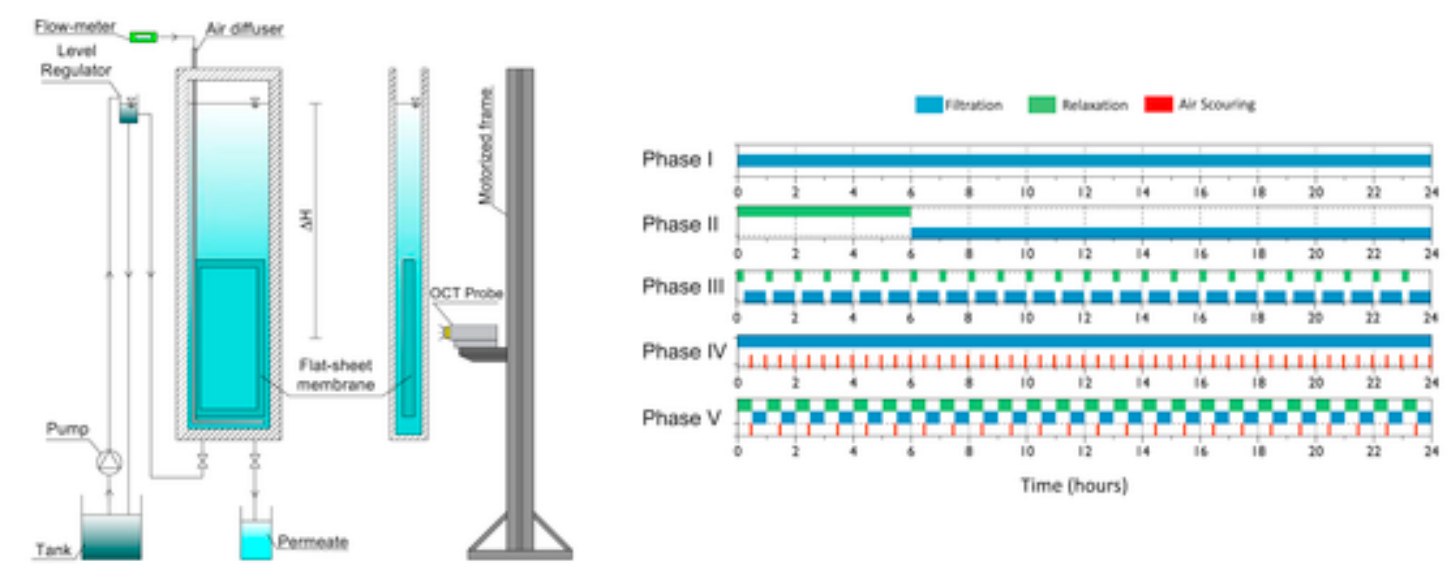

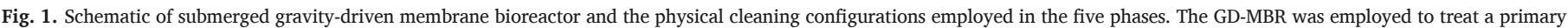
effluent, with an Optical Coherence Tomography (OCT) probe to monitor the evolution of the fouling layer in-situ during continuous operation. 
Table 1

Operating conditions of the GD-MBR reactor.

\begin{tabular}{|c|c|c|c|c|c|}
\hline & Phase (I) & Phase (II) & Phase (III) & Phase (IV) & Phase (V) \\
\hline \multirow[t]{2}{*}{ Air frequency } & - & - & - & $5 \min \mathrm{ON}$ & $5 \mathrm{~min}$ ON \\
\hline & - & - & - & $25 \mathrm{~min}$ OFF & $55 \mathrm{~min}$ OFF \\
\hline Daily aeration & - & - & - & $4 \mathrm{~h}$ & $2 \mathrm{~h}$ \\
\hline Air intensity & - & - & - & $8 \mathrm{~L} / \mathrm{min}$ & $8 \mathrm{~L} / \mathrm{min}$ \\
\hline $\mathrm{SAD}_{\mathrm{m}}$ & - & _- & - & $10 \mathrm{~m}^{3} / \mathrm{m}^{2} \mathrm{~h}$ & $10 \mathrm{~m}^{3} / \mathrm{m}^{2} \mathrm{~h}$ \\
\hline \multirow[t]{2}{*}{ Relaxation frequency } & - & $6 \mathrm{~h} \mathrm{ON}$ & $15 \min$ ON & - & $30 \mathrm{~min}$ ON \\
\hline & - & $18 \mathrm{~h} \mathrm{OFF}$ & $45 \mathrm{~min}$ OFF & - & $30 \mathrm{~min}$ OFF \\
\hline Daily filtration & 24 h $(100 \%)$ & $18 \mathrm{~h}(75 \%)$ & 18 h $(75 \%)$ & 24 h $(100 \%)$ & $12 \mathrm{~h}(50 \%)$ \\
\hline Daily average permeate & $0.90^{\mathrm{a}} \mathrm{L}$ & $0.67 \mathrm{~L}$ & $0.67 \mathrm{~L}$ & $1.07 \mathrm{~L}$ & $1.46 \mathrm{~L}$ \\
\hline DO & $<0.5 \mathrm{mg} / \mathrm{L}$ & $<0.5 \mathrm{mg} / \mathrm{L}$ & $<0.5 \mathrm{mg} / \mathrm{L}$ & $5.5-6 \mathrm{mg} / \mathrm{L}$ & $5.5-6 \mathrm{mg} / \mathrm{L}$ \\
\hline HRT & $90-205 \mathrm{~h}$ & $350-360 \mathrm{~h}$ & $370-380 \mathrm{~h}$ & $240-250 \mathrm{~h}$ & $150-160 \mathrm{~h}$ \\
\hline Days & $0-21$ & $21-35$ & $35-43$ & $43-51$ & $51-59$ \\
\hline
\end{tabular}

a Calculated after the achievement of a stable flux.

ter filtering the sample through a $0.45 \mu \mathrm{m}$ filter (Millipore, USA) with a TOC analyzer (TOC-V-CSH, Shimadzu, Japan), using the Non-purgeable organic carbon (NPOC) method. The DO was monitored using a bench-meter (WTW Multi 9430).

\subsection{Biomass morphology monitoring}

The morphology of the cake layer formed was monitored daily using a spectral-domain OCT system (GANYMEDE, Thorlabs), with a central wavelength of $930 \mathrm{~nm}$ and a $5 \mathrm{X}$ telecentric scan lens (LSM 03BB). The OCT probe was mounted on a motorized frame in order to control the imaging in a system of coordinates [11]. The 2D OCT scans were acquired with a size of $1750 \times 652$ pixel, corresponding to $4.00 \mathrm{~mm}$ (width) x $1.35 \mathrm{~mm}$ (depth). The 3D OCT scans were acquired with a size of $666 \times 666 \times 900$ pixels, corresponding to $4.0 \mathrm{~mm}$ (width) x $4.00 \mathrm{~mm}$ (length) x $1.80 \mathrm{~mm}$ (depth). At the end of Phase I, IV and V, the biomass was scanned in five different positions across the membrane height spaced $5 \mathrm{~cm}$ to each other. The cake layer morphology analysis was performed following the procedure reported in a previous study [5]. The biomass thickness was calculated by using a customized MATLAB code $[23,24]$. A color lookup table was applied in FiJi Software to the OCT $2 \mathrm{D}$ scans for visualization purposes. The visualization of the 3D OCT dataset was performed using Avizo.

\subsection{Hydraulic resistance model}

In this study, the hydraulic resistance was derived from permeate flux and transmembrane pressure (bar). The permeate flux was calculated using the following equation:

$J=\frac{\Delta \mathrm{V}}{\mathrm{A} \cdot \Delta \mathrm{t}}$

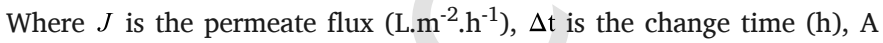
is the specific membrane filtration area $\left(\mathrm{m}^{2}\right)$ and $\Delta \mathrm{V}$ is the permeate volume (L) collected during $\Delta \mathrm{t}$. The total hydraulic resistance was calculated by using the following equation:

$R_{t o t}=\frac{\Delta \mathrm{P}}{\mu_{\mathrm{T}} \cdot \mathrm{J}}$

Where $R_{\text {tot }}$ is total hydraulic resistance $(1 / \mathrm{m}), \Delta \mathrm{P}$ is the transmembrane pressure (TMP), $\mu_{\mathrm{T}}$ is the viscosity of water ( $\mathrm{Pa} \mathrm{s}$ ) at temperature $\mathrm{T}\left({ }^{\circ} \mathrm{C}\right) . \Delta \mathrm{P}$ applied in this analysis was normalized to be the minimum driving force and expressed as the hydraulic head, corresponding to the water level above the middle point of the membrane module (i.e. 40 mbar). $\Delta \mathrm{P}$ was kept constant during the whole period of operation. The fouling layer resistance was calculated by Eq. (3), using the hy- draulic resistance in series model:

$R_{t o t}=R_{m}+R_{b}$

$R_{m}$ is the membrane hydraulic resistance $(1 / \mathrm{m})$, determined from the clean water flux by filtration of Milli-Q water with a clean membrane. In our case the resistance of the cake correspond to the biomass developed on the membrane surface, hence $R_{\text {cake }}=R_{b}$ [25]. The biomass hydraulic resistance $\left(R_{b}\right)$ is expressed as the product of the biomass thickness $\left(L_{b}\right)$, its density $\left(\rho_{b}\right)$ and its specific resistance $\left(\alpha_{b}\right)$ [26]. $L_{b}$ was calculated through the OCT scans [27].

$R_{b}=\alpha_{b} \cdot L_{b} \cdot \rho_{b}$

The biomass specific hydraulic resistance $\left(X_{s}\right)$ was introduced and defined as the division of the biomass hydraulic resistance $\left(R_{b}\right)$ by the biomass thickness $\left(L_{b}\right)$.

$X_{s}=\frac{R_{b}}{L_{b}}=\alpha_{b} \cdot \rho_{b}$

\subsection{Fouling analysis}

At the end of the $59 \mathrm{~d}$ operation, a destructive autopsy analysis was conducted after removing the module from the reactor. Fifteen membrane coupons (each $2 \times 2 \mathrm{~cm}$ ) were collected from the fouled module according to a predefined a grid drawn before operation started. The coupons sampled from the flat sheet membrane were inserted in 15 capped tubes containing $40 \mathrm{~mL}$ of autoclaved 1x phosphate-buffered saline $[28,29]$. The tubes were then inserted in an ultrasonic bath, with three cycles of $5 \mathrm{~min}$ of sonication followed by $10 \mathrm{~s}$ of vortex mixing. Characterization of the supernatants were conducted by analyzing the organic matter and measuring ATP.

The organic matter characterization was carried out by using liquid chromatography with organic carbon detection (LC-OCD, DOC-Labor, Germany). The main fractions identified by the LC-OCD technique are biopolymers (BP), humic substances (HS), building blocks (BB), low molecular weight (LMW) acids and neutrals. In the LC-OCD measurement, samples are supplied by a mobile phase at a flow rate of $1.5 \mathrm{~mL} /$ min to the chromatographic column [30]. A dual column was used with $2000 \mu \mathrm{L}$ injection volume and $180 \mathrm{~min}$ retention time.

ATP was measured using an ATP Analyzer (Celsis, USA), which applies the luciferin-luciferase bioluminescence reaction method. By filtering the sample with a $0.22 \mu \mathrm{m}$ filter, the total ATP can be divided into intracellular (or microbial) and extracellular ATP. The intracellular (or microbial) ATP was calculated from the difference between the total ATP and extracellular ATP (i.e. filtered sample) [28]. 


\section{Result and discussion}

\subsection{GD-MBR treating primary wastewater effluent}

In this study, the gravity-driven membrane bioreactor (GD-MBR) was fed with raw wastewater and operated continuously. Operating conditions consisted of five phases, corresponding to the five different physical cleaning strategies employed (Table 1 and Fig. 1). Phase I corresponded to the first 21 days of operation where no physical cleaning was employed and continuous filtration performed. The membrane performance during this initial phase is shown in Fig. 2. Two different trends were identified, a rapid decrease in flux (from $7.00-1.20 \mathrm{~L} \cdot \mathrm{m}^{-2} \cdot \mathrm{h}^{-1}$ ) was observed in the first $5 \mathrm{~d}$ of operation, followed by a slow decrease to a more stable flux $\left(0.80 \mathrm{~L} \cdot \mathrm{m}^{-2} \cdot \mathrm{h}^{-1}\right)$ in the remaining period (5-21 days).

The flux behavior observed in the first 21 days followed the characteristic trend previously reported for GDM processes $[11,12]$. However, the initial decay observed in this study was faster and the value of the stable flux was slightly lower compared to other studies. A stable flux of around $1.00 \mathrm{~L} \cdot \mathrm{m}^{-2} \cdot \mathrm{h}^{-1}$ was observed after 7 days of operation. The stable flux in a GDM process is governed by different factors such as biomass deposition, cake layer properties, membrane pore size, water head (i.e. pressure), and feed water quality. In this study, a UF membrane (20 KDa MWCO, Polysulfone) operating with a minimum pressure of $25 \mathrm{~cm}$ water head above the membrane module was tested to treat a primary wastewater effluent. The wastewater employed in this study was characterized by $150 \pm 40 \mathrm{mg} / \mathrm{L} \mathrm{COD}, 28 \pm 10 \mathrm{NTU}$ and $66 \pm 20 \mathrm{mg} / \mathrm{L}$ of SS (Table S1). The reactor was operated under very low-DO conditions and with relatively high HRT. In the initial phase of operation without cleaning the low value of the stable flux was mainly due to the high organic content of the feed treated by the GDM bioreactor.

Reports in the literature show that the stable flux in GDM processes decreases with increasing organic concentrations in the feed. Wang et al. [4], by using the same membrane pore size and a similar setup, observed a flux decrease from $4.00 \mathrm{~L} \cdot \mathrm{m}^{-2} \cdot \mathrm{h}^{-1}$ to $2.00 \mathrm{~L} \cdot \mathrm{m}^{-2} \cdot \mathrm{h}^{-1}$, while increasing the COD concentration of secondary wastewater effluent from $7.5 \mathrm{mg} / \mathrm{L}$ to $15 \mathrm{mg} / \mathrm{L}$. Peter-Varbanets et al. [12] observed a stable flux of $4.00 \mathrm{~L}^{-\mathrm{m}^{-2}} \cdot \mathrm{h}^{-1}$ treating diluted wastewater with a TOC of $12.5 \mathrm{mg}$ / L. Recently, S. Lee et al. [21] achieved a stable flux of $0.90 \mathrm{~L} \cdot \mathrm{m}^{-2} \cdot \mathrm{h}^{-1}$ treating wastewater with an organic concentration of 16-68 mg DOC/
L with a hydrostatic pressure of 30 mbar using a PVDF membrane with a MWCO of $30 \mathrm{kDa}$.

As shown by the OCT scans, the morphology of the biomass obtained in this study using real wastewater was similar to the one observed in previous GDM studies, with the presence of a looser top layer [11]. The amount of biomass deposited on the membrane increased significantly in the first days of operation (up to $50 \mu \mathrm{m}$ ) and then slowly increased until the end of phase I (21 days) (Fig. 3). In this period, without any cleaning strategy, a decrease of the biomass roughness was observed as the cake layer thickness increased, indicating the development of a more homogeneous and compact biomass structure [23].

\subsection{Introduction of physical cleaning strategies}

\subsubsection{Long relaxation (phase II)}

After phase I (21 days), four phases with different physical cleaning strategies were investigated. The first cleaning strategy was introduced without any action being taken on the membrane, where a $130 \mu \mathrm{m}$ thick biomass was already formed (Fig. 3). The first cleaning cycle consisted of using a long relaxation period (Table 1). This fouling mitigation strategy involved a negligible consumption of energy since it consists only in the temporary interruption of the flux [18]. In the first three phases the overall energy consumption was related to the feed pump consumption and corresponded to $0.005 \mathrm{kWh} / \mathrm{m}^{3}$. In this phase a long relaxation period with $6 \mathrm{~h}$ of relaxation every $18 \mathrm{~h}$ of filtration was chosen in order to study the biomass behavior during the absence of permeation in detail.

During this phase, no increase in performance was observed with respect to phase I, maintaining a steady flux of around $0.80 \mathrm{~L} \cdot \mathrm{m}^{-2} \cdot \mathrm{h}^{-1}$ (Fig. 4).

In fact, the biomass structure remained similar to phase I during the initial part of phase II, with an increase in thickness and decrease in roughness observed towards the end of phase II (Fig. 3). The first change in cake layer morphology was noticed in the OCT scans after 29 days, with the presence of a lower layer deposited on the membrane surface (Fig. 5). This layer was directly deposited on the membrane surface and appeared to have a mushroom-like structure, characteristic of biofilm development observed in other membrane systems [31].

A time-resolved analysis was therefore performed to have a better understanding of the mechanism and effect of relaxation on the biomass. The non-invasive monitoring by OCT allowed visualizing the bio-

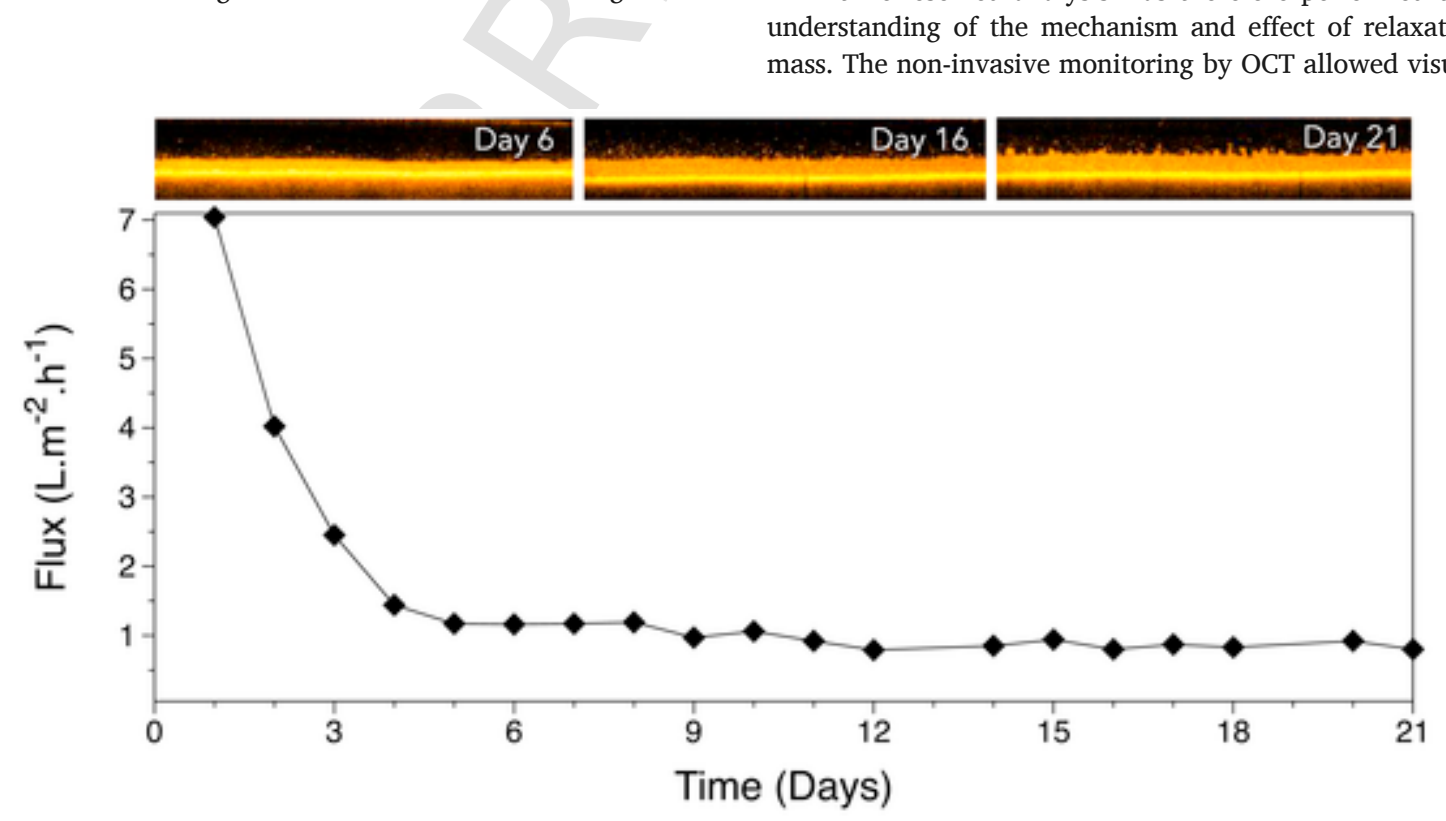

Fig. 2. Phase I: Flux decline from day 1-21, with images of biomass formed on d 6, 16, and 21. 

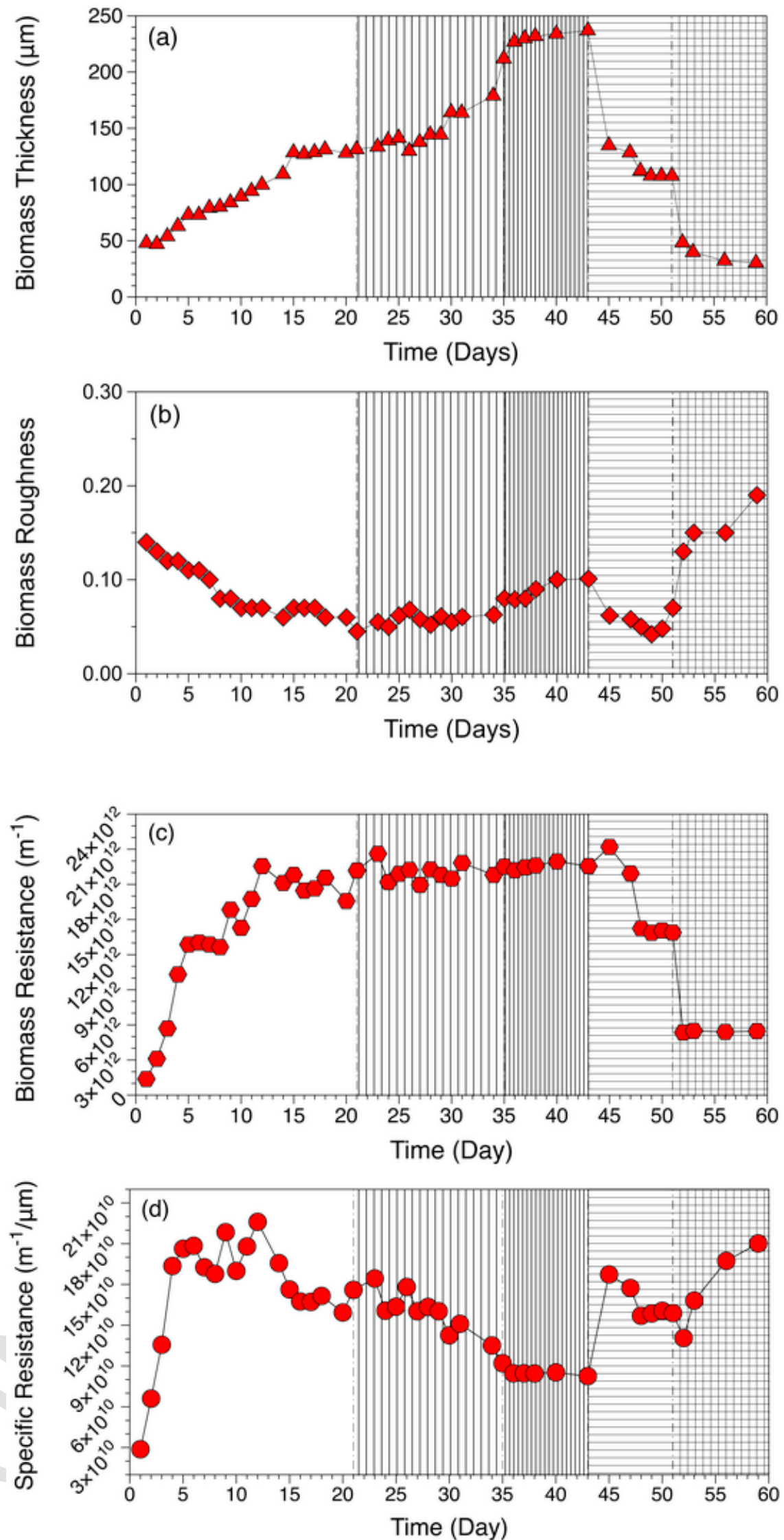

Fig. 3. Biomass descriptors during the 5 phases of operation: (a) thickness, (b) relative roughness, (c) hydraulic biomass resistance, (d) biomass specific hydraulic resistance. 


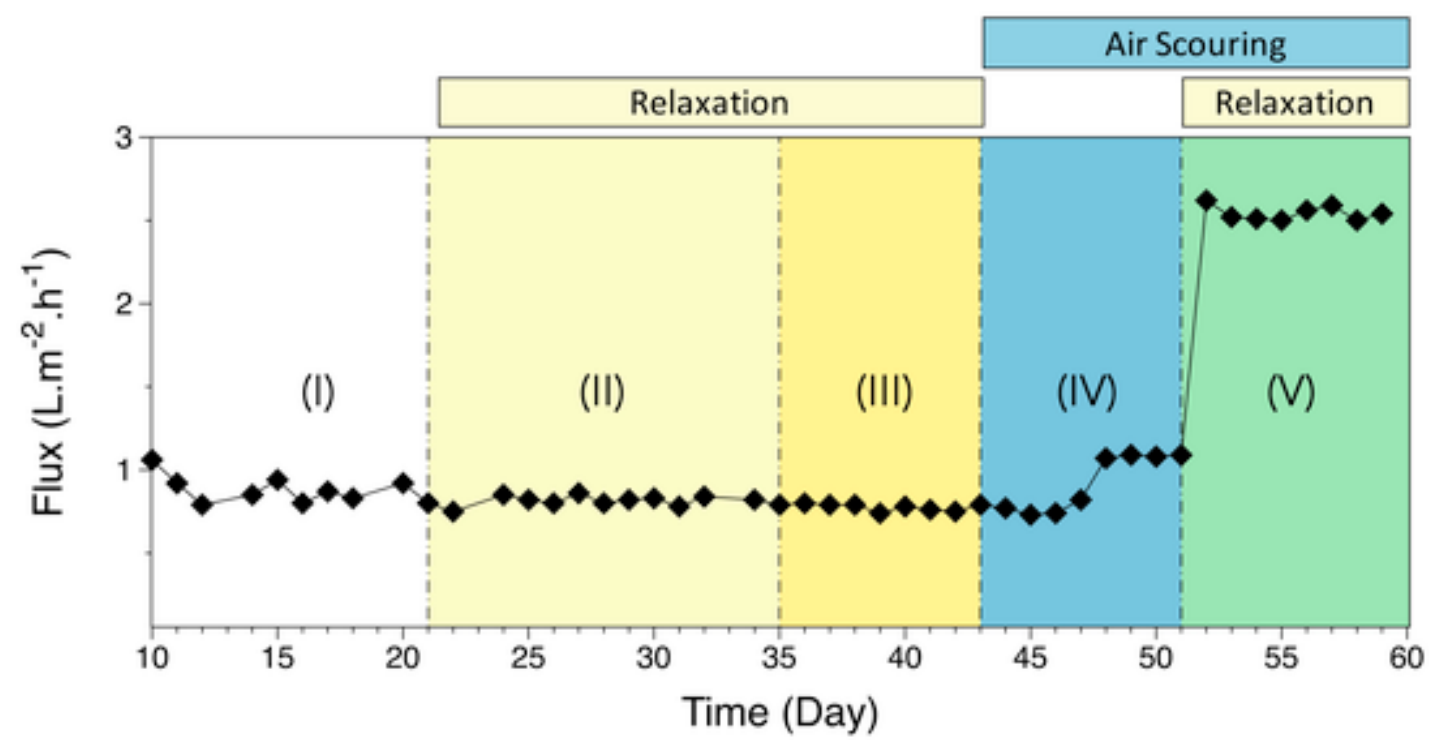

Fig. 4. Flux development over time, divided into five phases according to the fouling strategy employed.

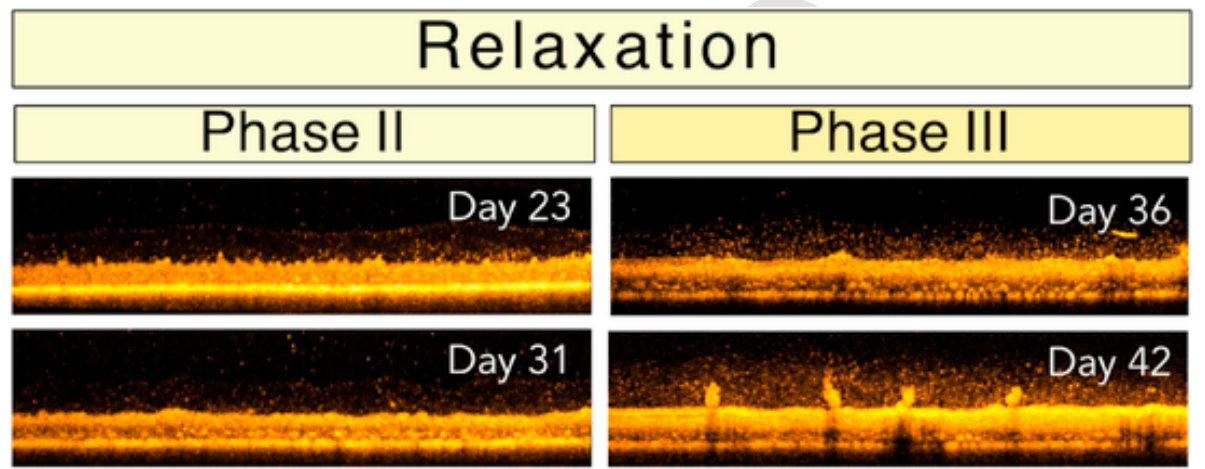

Fig. 5. Biomass morphology observed on the membrane surface during phases II and III, using relaxation/filtration with different frequencies.

mass response during a relaxation cycle. When permeation was interrupted (i.e. relaxation), the biomass expanded, loosening its structure and increasing in overall thickness up to $390 \mu \mathrm{m}$. Restarting filtration compressed the fouling layer again, returning the thickness to the initial value of $170 \mu \mathrm{m}$ (Fig. 6). In addition to the compression and decompression of the main layer, OCT images revealed a similar and more enhanced behavior for the upper cloudy looser layer. The time-resolved analysis demonstrated a plastic behavior of the biomass, decompressing and compressing as a function of permeation. The same behavior and trend were observed throughout the operation of phase II.

\subsubsection{Relaxation (phase III)}

In phase III the frequency of the cycles was reduced, applying a relaxation period of $15 \mathrm{~min}$ after $45 \mathrm{~min}$ of filtration. Phase II and III, although presenting different frequencies, accounted for the same ON/ OFF times when normalized to a daily operation, where the filtration was performed for $75 \%$ of daily time (Table 1). Therefore, phased III consisted in a higher frequency and shorter relaxation time. In this phase, the same steady membrane performance was registered, with no increase with respect to phase I.

After introducing a much higher relaxation/filtration frequency in phase III, the biomass thickness increased to $230 \mu \mathrm{m}$ (day 36) and remained somewhat constant during phase III (Fig. 3). Fig. 7 illustrates the typical biomass morphology during filtration observed under the different mitigation strategies applied using 3D OCT rendered images. As reported in the literature, the $3 \mathrm{D}$ visualization is a better representa- tive of the biomass formed in the system [23,32]. As shown in Fig. 7, despite the higher roughness, the biomass presented a heterogenous spatial distribution with a specific pattern. In fact, as highlighted the upper view of the 3D morphology (Fig. 8), the biomass peaks had the same height and were spaced approximatively $700 \mu \mathrm{m}$ from each other. A closer look suggested these peaks were embedded in a looser, cloudy layer with a filamentous structure characteristic of the EPS matrix (Fig. 8). It's worth mentioning that this matrix was visualized in 2D OCT scans as an ensemble of dots and was usually defined as a looser layer. Formation of the peaks on the upper part of the layer occurred during higher cycle frequencies with shorter relaxation time, however, it was unclear what aspects triggered this behavior. Despite the change in morphology and thickness compared to phase I, the two relaxation conditions tested during phases II and III showed a similar performance (i.e. flux, Fig. 4) and only small variation in hydraulic resistance by the biomass (Fig. 3c).

\subsubsection{Air scouring}

The relaxation phases were followed by applying air scouring in the GD-MBR system. Phase IV consisted of a scouring cycle with an aeration intensity of $8 \mathrm{~L} / \mathrm{min}$ for $5 \mathrm{~min}$ after $25 \mathrm{~min}$ of filtration. In this phase, the permeate production was not interrupted during the air scouring cycle, where the filtration was performed to the $100 \%$ of the total time. After one day of operation using this approach, the biomass thickness decreased by $57 \%$, from $240 \mu \mathrm{m}$ to $137 \mu \mathrm{m}$ (Fig. 3). When introducing air scouring the thickness of the fouling layer was re- 

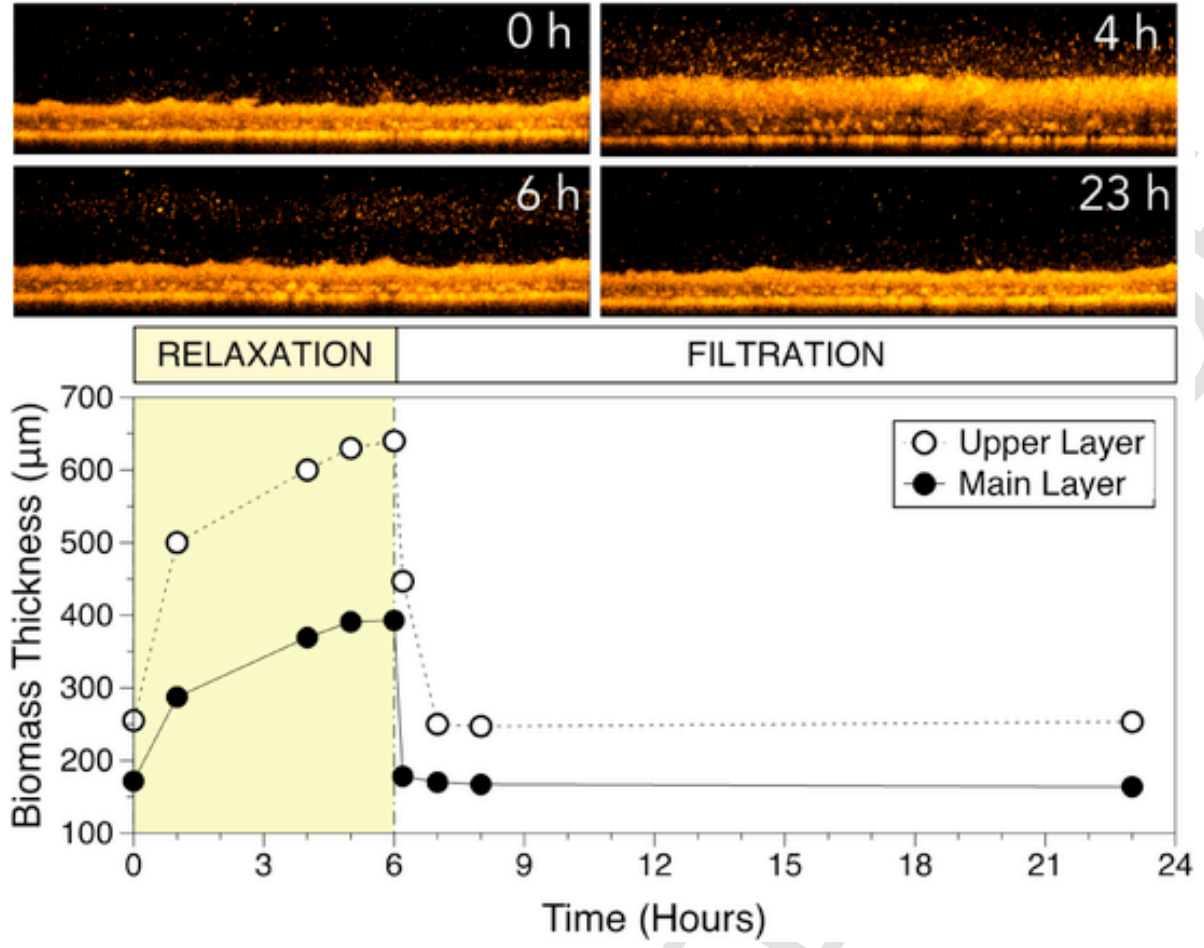

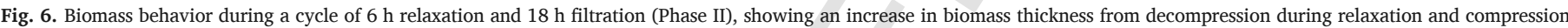
when filtration restarted.
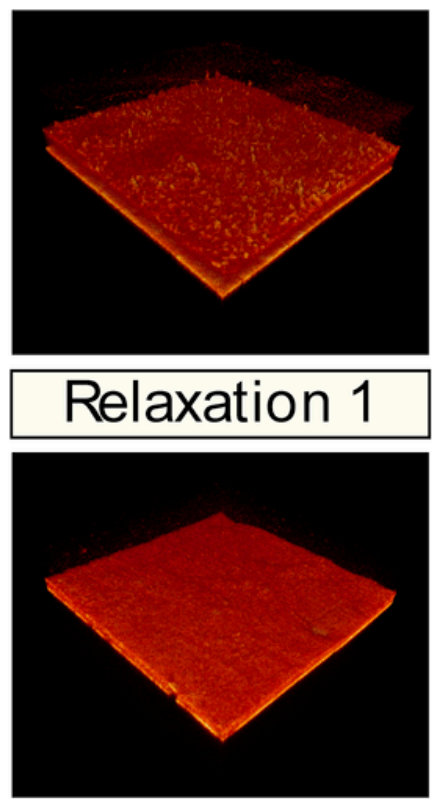

Air Scouring

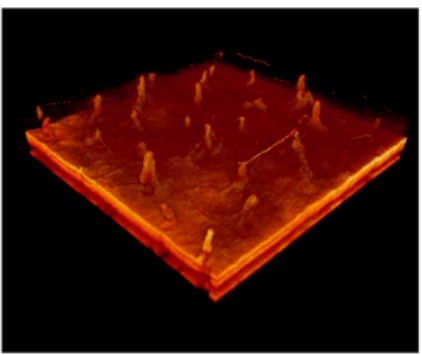

Relaxation 2

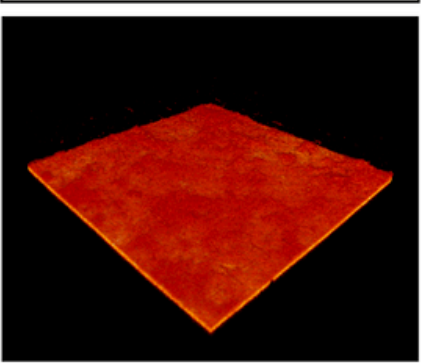

Combined

Fig. 7. 3D visualization of OCT scans, illustrating the biomass morphology developed under operation with different fouling mitigation strategies.

duced significantly and the biomass appeared denser and more compact with time (Fig. 9).

A slight change in membrane performance was observed during this phase. From day 43-47 a constant flux of $0.80 \mathrm{~L} \cdot \mathrm{m}^{-2} \cdot \mathrm{h}^{-1}$ was observed, followed by a $25 \%$ increase in flux from $0.80 \mathrm{~L} \cdot \mathrm{m}^{-2} \cdot \mathrm{h}^{-1}$ to $1.10 \mathrm{~L} \cdot \mathrm{m}^{-2} \cdot \mathrm{h}^{-1}$ on day 48 , after which the flux remained relatively constant until the end of this phase. Air scouring introduced in phase IV resulted in a thinner, more compact and homogeneous structure, and increased hy-

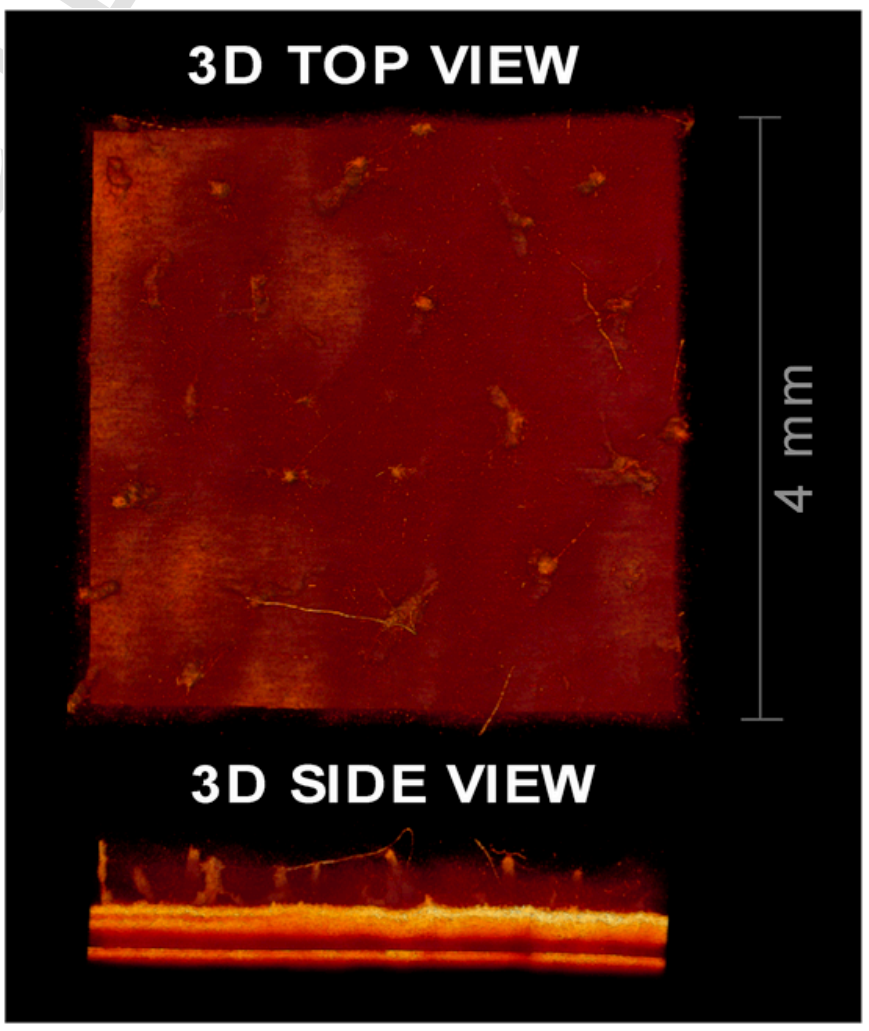

Fig. 8. 3D Biomass volume rendering during phase III ( $15 \mathrm{~min}$ relaxation after $45 \mathrm{~min}$ filtration), showing an irregular morphology.

draulic resistance. This observation was in agreement with reports in the literature $[21,33,34]$ where air scouring was not always beneficial on the membrane filtration performances due to formation of a thin, dense and less porous fouling layer. With increasing shear forces in- 


\section{Air Scouring (Phase IV)}
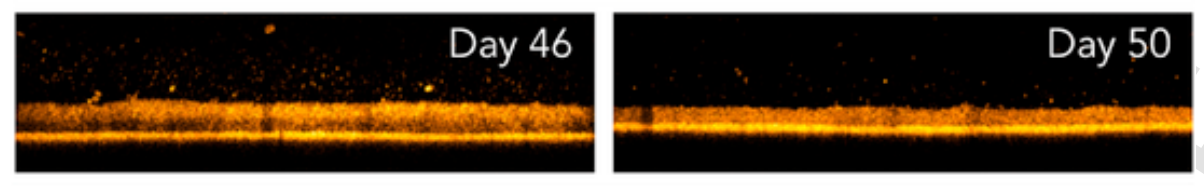

Combined Strategy (Phase V)
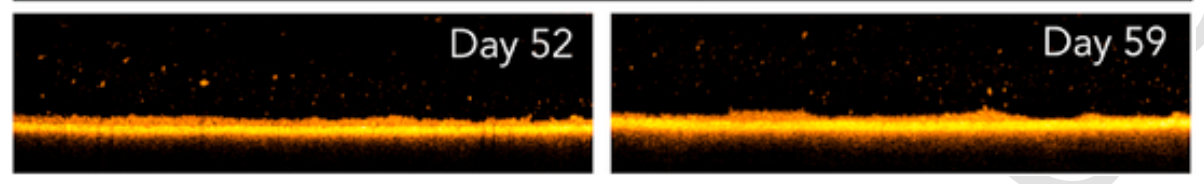

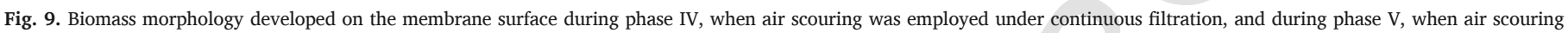
was applied at the end of the relaxation cycle.

duced by air scouring studies have shown that biofilms produce more EPS to adhere to the surface and become thinner and denser. It was noted that during this phase an increase of specific hydraulic resistance was observed (Fig. 3d). Indeed, by normalizing the hydraulic resistance for the thickness it was possible to assess a change in biomass proprieties with respect to phase II and III, where the biomass in phase IV provided more resistance to the overall filtration. Air scouring reduced the biomass thickness to a similar value $(132 \mu \mathrm{m})$ and specific hydraulic resistance as observed at the end of phase I and resulting in a similar flux (Fig. 3d). A further reduction on day 48 increased the flux and thus the overall resistance of the biomass layer. The results in this study indicated that the flux can be linked to the biomass morphology and proprieties in low-pressure GD-MBR systems.

\subsubsection{Combined application of relaxation and air scouring}

Relaxation and air scouring were applied together in phase $\mathrm{V}$ and operated from day 50-59. The combined strategy consisted of applying air scouring in the last $5 \mathrm{~min}$ of a $30 \mathrm{~min}$ relaxation cycle (Table 1). The overall air scouring duration in this period was reduced by $50 \%$ compared to the previous phase (IV). After one day of this combined strategy, the flux rapidly increased to $2.60 \mathrm{~L} \cdot \mathrm{m}^{-2} \cdot \mathrm{h}^{-1}$. This represented a $240 \%$ increase with respect to phase IV. The combined use of relaxation and air scouring showed a higher biomass removal compared to applying air scouring alone (Fig. 3), resulting in a significant reduction in biomass thickness of around $30 \mu \mathrm{m}$. The biomass roughness also increased which has previously been demonstrated to have a positive effect on membrane performance [24].

The combined action of air scouring at the end of a relaxation cycle was chosen based on the behavior of the biomass observed during relaxation (phases II and III). Air scouring was applied at the end of a relaxation cycle which corresponds to the expanded (i.e. highest thickness) biomass during the relaxation cycle (Fig. 6). The air scouring was assumed to be more efficient towards the end of a relaxation period as the biomass loosened and expanded in the absence of permeation. In this study, the air scouring intensity was kept the same as in phase IV but reduced from 10 to 5 min every hour. A significant removal of the biomass deposited on the membrane surface was observed, corresponding to a decrease in thickness from $108 \mu \mathrm{m}$ to $30 \mu \mathrm{m}$. In this phase, as shown in Fig. 3, the biomass presented a similar specific hydraulic resistance compared to phase IV. The comparable specific resistance observed in phase IV and V was due to the use of aeration that led to a change in the biomass proprieties with respect to the previous phases.

The increase in flux in this phase was linked to the decrease in thickness and the removal of biomass from some areas. Therefore, the $240 \%$ increase in flux achieved by the combined strategy represented a significant improvement in membrane performance compared to the fouling mitigation strategies employed in the other four phases. It is worth to mention that the flux enhancement with respect to phase IV was not associated to the amount of energy employed for fouling control. In fact, the daily aeration time in phase $\mathrm{V}$ was reduced by $50 \%$ with respect to phase IV, decreasing drastically the aeration energy consumption. The approach employed in this study allowed improving the cleaning efficiency and reducing the energy of air scouring by monitoring the biomass behavior during relaxation. Further studies are required to evaluate the impact of air scouring frequency and intensity on the process performance. A comprehensive trade-off analysis between the energy employed and the reactor performance will be necessary to assess the impact of the cleaning strategies on a pilot scale reactor $[1,35]$. In summary, the combined strategy employed in this study, consisting in applying the aeration at the end of a relaxation period when the biomass was expanded, resulted in an effective method to mitigate the fouling and to enhance the air scouring effect and overall membrane performances.

\subsection{Water quality parameters}

The feed and permeate water quality were measured throughout the experimental period to assess the removal efficiency of the GD-MBR process under the different fouling mitigation strategies investigated. In MBRs the overall removal efficiency is given by the sum of different contributions (i.e. physical separation, biomass activity, HRT, retention time, DO, temperature, etc). Previous GDM studies linked the removal efficiency to the thickness of the cake layer deposited on the membrane surface [4]. The DOC (mg/L) and turbidity (NTU) values for feed and permeate at the end of the respective phases are reported in Table 2 . The feed water was real wastewater collected from the wastewater treatment plant at KAUST and therefore varied a little during the

Table 2

Permeate and feed characteristics, DOC and Turbidity.

\begin{tabular}{lllllll}
\hline Parameter & & $\begin{array}{l}\text { Phase }^{\mathrm{a}} \\
\text { (I) }\end{array}$ & $\begin{array}{l}\text { Phase } \\
\text { (II) }\end{array}$ & Phase (III) & $\begin{array}{l}\text { Phase } \\
\text { (IV) }\end{array}$ & $\begin{array}{l}\text { Phase } \\
\text { (V) }\end{array}$ \\
\hline $\begin{array}{llllll}\text { DOC (mg/ } \\
\text { L) }\end{array}$ & Feed & 23.4 & 38.6 & 28.6 & 32.8 & 38.8 \\
& & & & & & \\
& Permeate & 9.8 & 11.6 & 5.6 & 5.3 & 4.1 \\
Turbidity & Removal & $58 \%$ & $70 \%$ & $80 \%$ & $84 \%$ & $89 \%$ \\
(NTU) & Feed & 17.5 & 38.0 & 21.0 & 37.2 & 28.9 \\
& Permeate & 4.3 & 3.7 & 2.2 & 2.4 & 2.1 \\
& Removal & $75 \%$ & $90 \%$ & $89 \%$ & $93 \%$ & $93 \%$
\end{tabular}

a The removal efficiency was calculated by counting only the last 3 days of Phase I. 
trial period (i.e. 23-39 mg DOC/L, 17.5-38.0 NTU). During phase I with continuous operation, around 58\% removal of DOC and 75\% turbidity was achieved. An increase in removal efficiency was observed with the introduction of the fouling mitigation strategies. Turbidity removal increased from $75 \%$ to approximately $90 \%$ with the introduction of the four physical cleaning strategies. The DOC removal increased from $58 \%$ to around 70, 80, 84 and 90\% for the respective phases. Except for phase II which was similar to phase I, the permeate quality in phases III, IV and $\mathrm{V}$ had a similar quality. The permeate quality in the last phases was characterized by a DOC concentration of $4.1 \pm 0.4 \mathrm{mg} / \mathrm{L}$ and a turbidity of $2.1 \pm 0.2$ NTU. The highest removal was observed for phase V, with a DOC removal of $89 \%$ and turbidity removal of $93 \%$. Lee et al. [21], observed a similar increase in permeate quality from a DOC of $9.4 \mathrm{mg} / \mathrm{L}$ to $2.6-4.4 \mathrm{mg} / \mathrm{L}$ with the introduction of intermittent air scouring cycles in a GD-MBR with biocarriers.

The different physical cleaning strategies introduced in the GD-MBR mode of operation impacted the biological performance and treatment efficiencies of the GD-MBR process. The cleaning strategies employed in this study also affected the DO concentration in the reactor and the HRT (Table 1). Long relaxation cycles (phase II and III) and low membrane fluxes led to an increase in HRT, which affected the organic loading rates, ultimately enhancing the organic removal due to the longer contact time. Introducing air scouring (phase IV and V) added an element of aeration which increased the DO in the reactor. The increase in DO concentration promoted aerobic biological activity which enhanced the removal of the biodegradable carbon. Intermittent aeration has previously been reported as a strategy to enhance carbon removal [21]. However, the positive effect of the aeration in phase IV was offset by

Table 3

Destructive characterization performed by membrane autopsy after 59 days of operation. Values were normalized for membrane area and volume of biomass deposited on the membrane surface (calculated non-destructively with OCT).

\begin{tabular}{lll}
\hline Normalized & $\begin{array}{l}\text { For Membrane Area }(X / \\
\left.\mathrm{cm}^{2}\right)\end{array}$ & $\begin{array}{l}\text { For Biomass Volume }(X / \\
\left.\mathrm{mm}^{3}\right)\end{array}$ \\
\hline $\begin{array}{l}\text { Total ATP } \\
\text { Extracellular }\end{array}$ & $3063\left(\mathrm{pg} / \mathrm{cm}^{2}\right)$ & $785\left(\mathrm{pg} / \mathrm{mm}^{3}\right)$ \\
ATP & $216\left(\mathrm{pg} / \mathrm{cm}^{2}\right)$ & $55\left(\mathrm{pg} / \mathrm{mm}^{3}\right)$ \\
Intracellular ATP & $2847\left(\mathrm{pg} / \mathrm{cm}^{2}\right)$ & $730\left(\mathrm{pg} / \mathrm{mm}^{3}\right)$ \\
DOC & $75.1\left(\mu \mathrm{g} / \mathrm{cm}^{2}\right)$ & $19.25\left(\mu \mathrm{g} / \mathrm{mm}^{3}\right)$ \\
BP & $41.1\left(\mu \mathrm{g} / \mathrm{cm}^{2}\right)$ & $10.53\left(\mu \mathrm{g} / \mathrm{mm}^{3}\right)$ \\
BB & $15.3\left(\mu \mathrm{g} / \mathrm{cm}^{2}\right)$ & $3.92\left(\mu \mathrm{g} / \mathrm{mm}^{3}\right)$ \\
LMW-N & $18.2\left(\mu \mathrm{g} / \mathrm{cm}^{2}\right)$ & $4.67\left(\mu \mathrm{g} / \mathrm{mm}^{3}\right)$ \\
LMW-A & $0.5\left(\mu \mathrm{g} / \mathrm{cm}^{2}\right)$ & $0.13\left(\mu \mathrm{g} / \mathrm{mm}^{3}\right)$ \\
\hline
\end{tabular}

a Hydrophilic DOC. a decrease of the biomass thickness and a decrease in HRT as continuous permeation was applied in this phase.

\subsection{Destructive biomass characterization (membrane autopsy)}

A membrane autopsy was conducted at the end of the experimental trial (day 59) on 15 samples collected from the fouled membrane module. Before the autopsy, the membrane was scanned in five positions along the height of the module (Fig S1). The biomass distribution observed across these five positions presented the same characteristics in terms of morphology and thickness, surprisingly, no biomass thickness gradient across the height of the membrane module was observed despite the gradient in driving force. The analytical results of the ex-situ destructive autopsy are shown in Table 3 and Fig S1 expressed for membrane area (i) and biomass volume (ii). While expressing the value for the membrane area represents the common practice, normalizing for the biomass volume was recently proposed by Fortunato et al. [28]. The approach integrated the in-situ characterization of the biomass with the destructive analysis, where the analytical parameters were divided by the biomass volume measured with the OCT in the reactor before the autopsy. This approach allowed quantifying the biological activity of the biomass deposited on the membrane surface. In this study, the calculated biomass values for total and intracellular (microbial) ATP were $785 \mathrm{pg} / \mathrm{mm}^{3}$ and $730 \mathrm{pg} / \mathrm{mm}^{3}$ respectively. In this study, due to the use of the primary wastewater effluent as feed, the biomass presented an higher biological activity compared to previous studies [4].

The DOC, normalized for the biomass volume, was found to be $19.25 \mu \mathrm{g} / \mathrm{mm}^{3}$, which was higher than a value of $4.6 \mu \mathrm{g} / \mathrm{mm}^{3}$ calculated in a previous GD-MBR study treating secondary synthetic effluent [28]. The difference in the amount of hydrophilic organic content per $\mathrm{mm}^{3}$ of biomass and its relative abundance was related to the different types of influents used in the two studies (i.e. primary vs secondary). Fig. 10 shows the relative abundance of the organic fractions of the foulants in the wastewater and deposited on the membrane. In the deposited biomass. bio-polymers (BP) constituted 55\% of the fouling layer, while building-blocks (BB) and low molecular weight neutrals (LMW-N) constituted 22 and $21 \%$ respectively. The organic distribution in the fouling layer was only partially linked to the organic composition of the feed employed in the study. In fact, while the ratio of BB and LMW-N were similar, a significant increase in the relative composition of BP in the deposited biomass was observed. The BPs constituted only around $20 \%$ of the total organic compounds in the wastewater, indicating that BP accumulated over time on the membrane surface. These results were in agreement with previous studies where the BPs were linked to an increase in fouling and reduction of flux rates in low-pressure membrane processes [36].

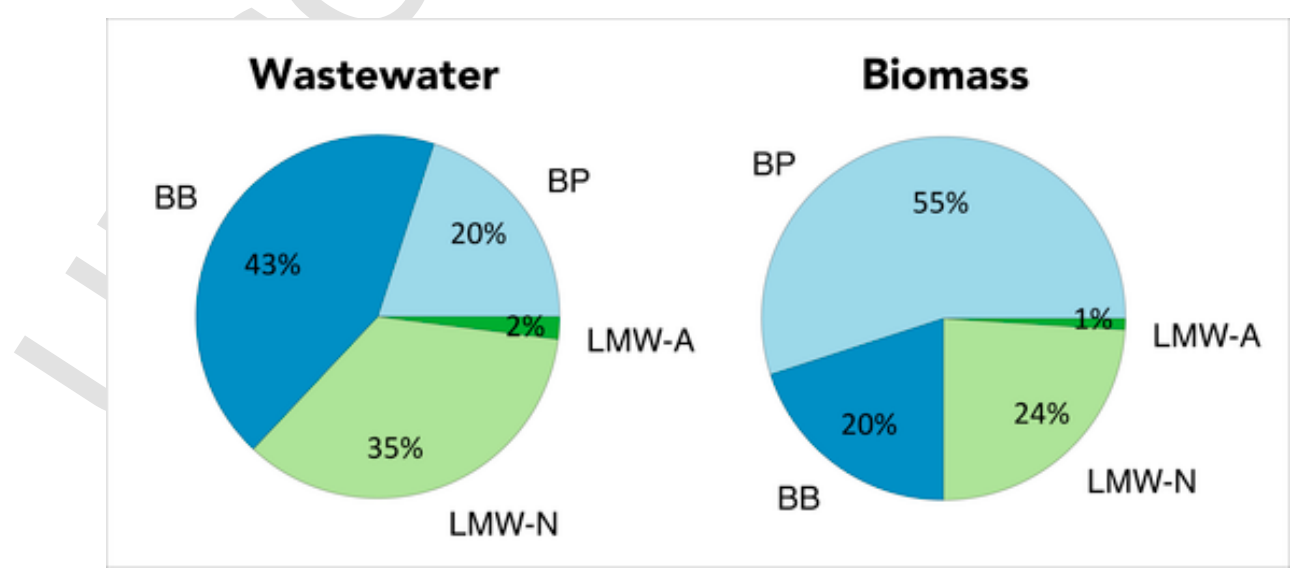

Fig. 10. The relative abundance of the hydrophilic organic fraction in wastewater and biomass deposited on the membrane. 


\section{Conclusion}

In this study, a gravity-driven membrane bioreactor was tested for the treatment of primary wastewater effluent. The effect of relaxation and air scouring on the biomass developed on the membrane surface was assessed. Based on the results observed, the following conclusions can be made:

- OCT allowed visualizing and evaluating the impact of the physical cleaning on the biomass morphology and biomass proprieties in real-time.

- Relaxation did not improve the membrane performance but led to a significant change in biomass morphology and biomass proprieties, impacting: thickness, roughness, spatial distribution and biomass specific hydraulic resistance.

- The biomass showed an elastic behavior during relaxation cycles, expanding its volume (i.e. $230 \%$ increase in thickness) with the absence of permeation, then becoming compressed again when filtration restarted.

- The use of air scouring at the end of a relaxation cycle, when the biomass was expanded, led to a higher biomass removal from the membrane surface with a significative increase in performance (i.e. $250 \%$ increase in flux).

- Air scouring under continuous filtration did not enhance the performance, the decrease in biomass thickness $(\sim 50 \%)$ was offset by an increase in biomass specific hydraulic resistance.

- Over time, the biopolymers accumulated on the membrane surface becoming the most abundant organic fraction (55\%) in the fouling layer.

\section{CRediT authorship contribution statement}

Luca Fortunato: Conceptualization, Supervision, Writing - original draft, Formal analysis, Writing - review \& editing, Visualization. Luigi Ranieri: Investigation, Data curation, Writing - original draft. Vincenzo Naddeo: Resources. TorOve Leiknes: Writing - review \& editing.

\section{Declaration of competing interest}

The authors declare that they have no known competing financial interests or personal relationships that could have appeared to influence the work reported in this paper.

\section{Acknowledgments}

The research reported in this publication was supported by funding from King Abdullah University of Science and Technology (KAUST)

\section{Appendix A. Supplementary data}

Supplementary data to this article can be found online at https://doi. org/10.1016/j.memsci.2020.118261.

\section{References}

[1] W Pronk, A Ding, E Morgenroth, N Derlon, P Desmond, M Burkhardt, et al., Gravity-driven membrane filtration for water and wastewater treatment: a review, Water Res. (2019) 553-565, doi:10.1016/j.watres.2018.11.062.

[2] M Peter-Varbanets, R Johnston, R Meierhofer, F Kage, W Pronk, Gravity-driven membrane disinfection for household drinking water treatment, Futur. Water, Sanit. Hyg. Low-Income Ctries. Innov. Adapt. Engagem. A Chang. World - Proc. 35th, WEDC Int. Conf., 2011, https://www2.scopus.com/inward/record. uri?eid $=2$-s2.0-84891654319\&partnerID $=40 \&$ md5 = e25b37787259eba174e602de73862c88.

[3] A Ding, J Wang, D Lin, R Zeng, S Yu, Z Gan, et al., Effects of GAC layer on the performance of gravity-driven membrane filtration (GDM) system for rainwater recycling, Chemosphere 191 (2018) 253-261, doi:10.1016/ j.chemosphere.2017.10.034.

[4] Y Wang, L Fortunato, S Jeong, T O Leiknes, Gravity-driven membrane system for secondary wastewater effluent treatment: filtration performance and fouling characterization, Separ. Purif. Technol. 184 (2017) 26-33, doi:10.1016/ j.seppur.2017.04.027.

[5] L Fortunato, S Jeong, T Leiknes, Time-resolved monitoring of biofouling development on a flat sheet membrane using optical coherence tomography, Sci. Rep. 7 (2017) 15, doi:10.1038/s41598-017-00051-9.

[6] A Ding, H Liang, G Li, I Szivak, J Traber, W Pronk, A low energy gravity-driven membrane bioreactor system for grey water treatment: permeability and removal performance of organics, J. Membr. Sci. 542 (2017) 408-417, doi:10.1016/ j.memsci.2017.08.037.

[7] E Akhondi, B Wu, S Sun, B Marxer, W Lim, J Gu, et al., Gravity-driven membrane filtration as pretreatment for seawater reverse osmosis: linking biofouling layer morphology with flux stabilization, Water Res. 70 (2015) 158-173, doi:10.1016/ j.watres.2014.12.001.

[8] B Wu, T Christen, H S Tan, F Hochstrasser, S R Suwarno, X Liu, et al., Improved performance of gravity-driven membrane filtration for seawater pretreatment: implications of membrane module configuration, Water Res. 114 (2017) 59-68, doi:10.1016/j.watres.2017.02.022.

[9] H Chang, B Liu, H Wang, S-Y Zhang, S Chen, A Tiraferri, et al., Evaluating the performance of gravity-driven membrane filtration as desalination pretreatment of shale gas flowback and produced water, J. Membr. Sci. 587 (2019) 117187, doi:10.1016/J.MEMSCI.2019.117187.

[10] S Shao, D Shi, Y Li, Y Liu, Z Lu, Z Fang, et al., Effects of water temperature and light intensity on the performance of gravity-driven membrane system, Chemosphere 216 (2019) 324-330, doi:10.1016/J.CHEMOSPHERE.2018.10.156.

[11] L Fortunato, A Qamar, Y Wang, S Jeong, T Leiknes, In-situ assessment of biofilm formation in submerged membrane system using optical coherence tomography and computational fluid dynamics, J. Membr. Sci. 521 (2017) 84-94, doi:10.1016/j.memsci.2016.09.004.

[12] M Peter-Varbanets, F Hammes, M Vital, W Pronk, Stabilization of flux during dead-end ultra-low pressure ultrafiltration, Water Res. 44 (2010) 3607-3616, doi:10.1016/j.watres.2010.04.020.

[13] M Wagner, N P Ivleva, C Haisch, R Niessner, H Horn, Combined use of confocal laser scanning microscopy (CLSM) and Raman microscopy (RM): investigations on EPS - Matrix, Water Res. 43 (2009) 63-76, doi:10.1016/J.WATRES.2008.10.034.

[14] C Sun, L Fiksdal, A Hanssen-Bauer, M B Rye, T Leiknes, Characterization of membrane biofouling at different operating conditions (flux) in drinking water treatment using confocal laser scanning microscopy (CLSM) and image analysis, J. Membr. Sci. 382 (2011) 194-201, doi:10.1016/j.memsci.2011.08.010.

[15] J-G Lee, Y Jang, L Fortunato, S Jeong, S Lee, T Leiknes, et al., An advanced online monitoring approach to study the scaling behavior in direct contact membrane distillation, J. Membr. Sci. 546 (2018), doi:10.1016/j.memsci.2017.10.009.

[16] M Peter-Varbanets, J Margot, J Traber, W Pronk, Mechanisms of membrane fouling during ultra-low pressure ultrafiltration, J. Membr. Sci. 377 (2011) 42-53, doi:10.1016/j.memsci.2011.03.029.

[17] M L Christensen, T V Bugge, B H Hede, M Nierychlo, P Larsen, M K Jørgensen, Effects of relaxation time on fouling propensity in membrane bioreactors, J. Membr. Sci. 504 (2016) 176-184, doi:10.1016/J.MEMSCI.2016.01.006.

[18] L Fortunato, A F Lamprea, T Leiknes, Evaluation of membrane fouling mitigation strategies in an algal membrane photobioreactor (AMPBR) treating secondary wastewater effluent, Sci. Total Environ. (2019) 134548, doi:10.1016/ J.SCITOTENV.2019.134548.

[19] J Wu, P Le-Clech, R M Stuetz, A G Fane, V Chen, Effects of relaxation and backwashing conditions on fouling in membrane bioreactor, J. Membr. Sci. 324 (2008) 26-32, doi:10.1016/j.memsci.2008.06.057.

[20] E Braak, M Alliet, S Schetrite, C Albasi, Aeration and hydrodynamics in submerged membrane bioreactors, J. Membr. Sci. 379 (2011) 1-18, doi:10.1016/ J.MEMSCI.2011.06.004.

[21] S Lee, M Sutter, M Burkhardt, B Wu, T H Chong, Biocarriers facilitated gravity-driven membrane (GDM) reactor for wastewater reclamation: effect of intermittent aeration cycle, Sci. Total Environ. 694 (2019) 133719, doi:10.1016/ J.SCITOTENV.2019.133719.

[22] I Ivanovic, T Leiknes, Impact of aeration rates on particle colloidal fraction in the biofilm membrane bioreactor (BF-MBR), Desalination 231 (2008) 182-190, doi:10.1016/J.DESAL.2007.11.046.

[23] L Fortunato, M Li, T Cheng, Z U Rehman, W Heidrich, T Leiknes, Cake layer characterization in activated sludge membrane bioreactors: real-time analysis, J. Membr. Sci. 578 (2019) 163-171, doi:10.1016/J.MEMSCI.2019.02.026.

[24] L Fortunato, N Pathak, Z Ur Rehman, H Shon, T Leiknes, Real-time monitoring of membrane fouling development during early stages of activated sludge membrane bioreactor operation, Process Saf. Environ. Protect. 120 (2018) 313-320, doi:10.1016/J.PSEP.2018.09.022.

[25] N Derlon, A Grütter, F Brandenberger, A Sutter, U Kuhlicke, T R Neu, et al., The composition and compression of biofilms developed on ultrafiltration membranes determine hydraulic biofilm resistance, Water Res. 102 (2016) 63-72, doi:10.1016/J.WATRES.2016.06.019.

[26] J Busch, A Cruse, W Marquardt, Modeling submerged hollow-fiber membrane filtration for wastewater treatment, J. Membr. Sci. 288 (2007) 94-111, doi:10.1016/J.MEMSCI.2006.11.008.

[27] J Park, S Lee, J You, S Park, Y Ahn, W Jung, et al., Evaluation of fouling in nanofiltration for desalination using a resistance-in-series model and optical coherence tomography, Sci. Total Environ. 642 (2018) 349-355, doi:10.1016/ J.SCITOTENV.2018.06.041.

[28] L Fortunato, S Jeong, Y Wang, A R Behzad, T Leiknes, Integrated approach to characterize fouling on a flat sheet membrane gravity driven submerged membrane bioreactor, Bioresour. Technol. 222 (2016) 335-343, doi:10.1016/ j.biortech.2016.09.127. 
[29] S Jeong, G Naidu, R Vollprecht, T Leiknes, S Vigneswaran, In-depth analyses of organic matters in a full-scale seawater desalination plant and an autopsy of reverse osmosis membrane, Separ. Purif. Technol. 162 (2016) 171-179, doi:10.1016/j.seppur.2016.02.029.

[30] S Jeong, S-J Kim, C Min Kim, S Vigneswaran, T Vinh Nguyen, H-K Shon, et al., A detailed organic matter characterization of pretreated seawater using low pressure microfiltration hybrid systems, J. Membr. Sci. 428 (2013) 290-300, doi:10.1016/ j.memsci.2012.11.019.

[31] C Dreszer, A D Wexler, S Drusová, T Overdijk, A Zwijnenburg, H-C Flemming, et al., In-situ biofilm characterization in membrane systems using Optical Coherence Tomography: formation, structure, detachment and impact of flux change, Water Res. 67 (2014) 243-254, doi:10.1016/j.watres.2014.09.006.

[32] L Fortunato, S Bucs, R V Linares, C Cali, J S Vrouwenvelder, T Leiknes, Spatially-resolved in-situ quantification of biofouling using optical coherence tomography (OCT) and 3D image analysis in a spacer filled channel, J. Membr. Sci. 524 (2017) 673-681, doi:10.1016/j.memsci.2016.11.052.

[33] A Ding, H Liang, G Li, N Derlon, I Szivak, E Morgenroth, et al., Impact of aeration shear stress on permeate flux and fouling layer properties in a low pressure membrane bioreactor for the treatment of grey water, J. Membr. Sci. 510 (2016) 382-390, doi:10.1016/J.MEMSCI.2016.03.025.

[34] S Jabornig, S M Podmirseg, A novel fixed fibre biofilm membrane process for on-site greywater reclamation requiring no fouling control, Biotechnol. Bioeng. 112 (2015) 484-493, doi:10.1002/bit.25449.

[35] N Tangsubkul, K Parameshwaran, S Lundie, A G Fane, T D Waite, Environmental life cycle assessment of the microfiltration process, J. Membr. Sci. 284 (2006) 214-226, doi:10.1016/J.MEMSCI.2006.07.047.

[36] E Filloux, H Gallard, J-P Croue, Identification of effluent organic matter fractions responsible for low-pressure membrane fouling, Water Res. 46 (2012) 5531-5540, doi:10.1016/J.WATRES.2012.07.034. 